\title{
Integrating radiosensitive genes improves prediction of radiosensitivity or radioresistance in patients with oesophageal cancer
}

\author{
QIUNING ZHANG ${ }^{1,2}$, ZHITONG BING ${ }^{3,4}$, JINHUI TIAN $^{3,4}$, XIAOHU WANG $^{1,2}$, \\ RUIFENG LIU ${ }^{1,2}$, YI LI ${ }^{1}$, YARONG KONG ${ }^{1}$ and YAN YANG ${ }^{2}$ \\ ${ }^{1}$ Department of Radiation Oncology, The First Clinical Medical College of Lanzhou University, Lanzhou, Gansu 730000; \\ ${ }^{2}$ The First Clinical Medical College of Lanzhou University, Gansu Provincial Cancer Hospital; \\ ${ }^{3}$ Evidence Based Medicine Center, School of Basic Medical Science of Lanzhou University, Lanzhou, Gansu 730050; \\ ${ }^{4}$ Department of Computational Physics, Institute of Modern Physics of Chinese Academy of Sciences, \\ Lanzhou, Gansu 730000 P.R. China
}

Received February 26, 2018; Accepted March 8, 2019

DOI: $10.3892 / \mathrm{ol} .2019 .10240$

\begin{abstract}
Oesophageal cancer is a serious disease worldwide. In China, the incidence of esophageal cancer was reported to be $\sim 478,000$ in 2015. In the same year, the incidence of esophageal cancer in the United States was $~ 16,910$. Radiotherapy serves as an important tool in the treatment of oesophageal cancer, and although radiation therapy has progressed over time, the prognosis of the majority of patients with oesophageal cancer remains poor. Additionally, the sensitivity of patients with oesophageal cancer to radiotherapy and chemotherapy is not yet clear. Although there are a number of studies on the radiosensitivity of oesophageal cancer cell lines, the vastly different results from different cell lines make them unreliable to use as a guide in clinical practice. Therefore, a common radiosensitive gene signature may provide more reliable results, and using different combinations of common gene signatures to predict the outcome of patients with oesophageal cancer may generate a unique gene signature in oesophageal cancer. In the present study, the radiosensitive index and prognostic index were calculated to predict clinical outcomes. The prognostic index of a 41-gene signature combination is the largest combination of gene signatures used for classifying oesophageal cancer patients into radiosensitive (RS) and radioresistance (RR) groups, to the best of our knowledge, and this gene signature was more effective in patients classified as having Stage III oesophageal cancer. Furthermore, four genes (carbonyl reductase 1, serine/threonine kinase PAK2, ras-related protein Rab
\end{abstract}

Correspondence to: Professor Xiaohu Wang, Department of Radiation Oncology, The First Clinical Medical College of Lanzhou University, 222 Tianshui Road, Lanzhou, Gansu 730000, P.R. China E-mail: xhwanggansu@163.com

Key words: oesophageal cancer, radiosensitive gene signature, prognosis, clinical outcome, prognostic index
13 and twinfilin-1) may be sufficient to classify patients into either RS or RR. Subsequent to gene enrichment analysis, the cell communication pathway was significantly different between RS and RR groups in oesophageal cancer. These results may provide useful insights in improving radiotherapy strategies in clinical decisions.

\section{Introduction}

Oesophageal cancer remains a major national and global health problem. In the United States in 2016, oesophageal cancer accounted for $>15,000$ mortalities (1). In China in 2015 , the incidence of oesophageal cancer was $\sim 478,000$, and the number of mortalities was estimated to be $\sim 375,000$ (2). Surgery, chemotherapy and radiotherapy are the primary strategies for patient treatment at present (3). Radiation therapy has broad applications as a vital strategy for shrinking tumours or treating regional disease in oesophageal cancer (4). Current technologies employed in radiotherapy have led to a number of advanced methods for improving treatment; however, the prognosis of oesophageal cancer remains poor, and the sensitivity of patients towards radiation is unknown (5). In the transition towards an era of personalized medicine, a powerful tool that assists clinicians in assessing which individuals are likely to be benefit from radiotherapy does not exist. In consideration of the heterogeneity between various tumour types, even for patients with the same tumour type, prognostic and therapy-predictive molecular markers are essential to improve decisions regarding cancer therapy. At the molecular level, numerous genes are responsive to radiation exposure, and a recent study proposed that identifying the gene signature may predict precise radiotherapy (6). In the past few decades, predictive radiosensitivity techniques have been developed and tested (7). In cell line experiments, the values of the surviving fraction of cells at [2] Gy(SF)2, SF5 and SF8 are defined as indicators for distinguishing radiosensitivity (RS) and radioresistance (RR), whereas patients are defined as RS and RR based on the clinical outcome (overall survival 
and recurrence rate) (8). However, the majority of studies on the radiosensitivity of oesophageal cancer are primarily dependent on high-throughput microarrays to assay differential gene expression between RS and RR oesophageal cancer cell lines, and different cell lines predict markedly different RS and RR biomarkers (9-11). Although these studies may contribute to an improved understanding of the biological mechanisms underlying the development and progression of cancer to a certain extent, it is difficult to practically apply these to clinical decision-making on whether radiotherapy is an appropriate means of treatment, based on the mixed results of in vitro assays.

In the present study, two common radiosensitive gene signatures, which were previously validated by clinical data, were utilised $(6,7)$. The two types of gene signatures from different sources of radiosensitive genes were used to analyse the gene expression and clinical data of patients with oesophageal cancer. Eschrich et al (12) and Kim et al (13) proposed two different gene signatures for predicting radiosensitivity. Eschrich et al (12) used a panel of 48 human cancer cell lines to propose a radiosensitivity index (RSI), which was modelled as a function of the combination of gene expression, tissue of origin, and ras and $p 53$ status to correlate the surviving fraction of cells at $2 \mathrm{~Gy}(\mathrm{SF} 2)$. The model developed by Eschrich et al (12) predicted an RSI (10 genes), which was directly proportional to tumour radioresistance (12). A high level of RSI represents radioresistance, thus allowing for the successful prediction of a number of types of primary cancer (14-20). Although the authors previously predicted the radiosensitivity of oesophageal cancer, the sample sizes were too small $(\mathrm{n}=12)$, and this may have resulted in a poor prediction of the overall survival of the 12 patients with oesophageal cancer (21). Kim et al (13) proposed a radiosensitivity gene signature which included 31 genes based on the integrated results of four different microarray experiments. The gene signature demonstrated promising results for predicting the radiosensitivity of cancer cells; however, it has only been validated in glioblastoma. Therefore, in the present study, RSI and the 31-gene signature have been utilized to predict the outcomes of patients with oesophageal cancer using data obtained from The Cancer Genomic Atlas (TCGA).

Patients with cancer who respond to radiotherapy typically exhibit a favourable prognosis compared with those with a radioresistant cancer. Therefore, it is hypothesized that the gene expression profile of patients with oesophageal cancer may allow for the classification of individuals into RS and RR groups. In the present study, a 31-gene signature and RSI were used as predictive biomarkers for predicting the overall survival of patients with oesophageal cancer. The results obtained from the two different types of radiosensitivity gene signatures utilised did not exhibit any overlap. Thus, the signatures were combined to improve the estimation of overall survival in patients with oesophageal cancer, based on a dataset obtained from TCGA. The dataset contained information on 152 patients who received radiotherapy (https://xenabrowser. net/datapages/?cohort=GDC\%20TCGA\%20Esophageal $\% 20$ Cancer\%20(ESCA)\&removeHub=https $\% 3 \mathrm{~A} \% 2 \mathrm{~F} \% 2 \mathrm{Fxena}$. treehouse.gi.ucsc.edu\%3A443). Multivariate Cox regression analyses were used to determine the key genes for predicting $\mathrm{RS}$ and RR in patients with oesophageal cancer.

\section{Materials and methods}

Clinical data and gene expression data collection. Data of patients with oesophageal cancer were downloaded from TCGA data portal (https://portal.gdc.cancer.gov/). Among the cases with the gene expression profiles and clinical indexes, there were 152 cases with effective radiotherapy information, which were used for further analysis. The gene signatures associated with radiosensitivity were aggregated from two previous publications $(12,13)$ and there were no instances of overlap in the gene signatures. Eschrich et al (12) indicated a linear combination of 10 genes for predicting RS and RR, whereas Kim et al (13) identified 31 genes integrated from four different platforms for classifying the level of sensitivity of cancer cell lines after receiving radiotherapy.

Statistical analysis for clinical data and gene expression data. Univariate survival analysis was used to determine thedemographic and clinical factors associated with the overall survival time of patients with oesophageal cancer among 8 factors: Age, sex, histological type, radiotherapy, tumour status, smoking history, alcohol history, and Tumor-Node-Metastasis (TNM) stage. Only clinical factors with $\mathrm{P} \leq 0.05$ (log-rank test) were analysed using a multivariate Cox regression analysis. The correlation between overall survival time and gene expression using the univariate Cox regression for each gene from the two gene signatures was used to obtain a prognostic index (PI) derived from the linear combination of gene expression and the coefficient of Cox regression.

To generate an improved model of biomarkers for predicting the RS or RR classification of patients with oesophageal cancer, the two gene signatures were combined into a novel model. Multivariate Cox regression was used to calculate the P-value of the combination of all the genes in the 41-gene signature. A combined gene-signature from two sources was used. One part of gene signature was obtained from 10 radiosensitive biomarkers and the other part was obtained from 31 radiosensitive biomarkers. Genes with $\mathrm{P}<0.1$ were selected using multivariate Cox regression $(22,23)$. These genes were used as a gene signature for predicting RS and RR. The PI values derived from different gene combinations were ranked according to the hazard ratio (HR) and P-value of the log-rank test. The high-risk and low-risk groups divided by the median PI value, which was estimated by the HR and the P-value of the log-rank test. Thus, a higher HR and smaller P-value represented an improved PI.

$R S I$. RSI is a rank-based linear regression algorithm proposed by Eschrich et al (12): RSI=-0.0090008 x androgen receptor $(A R)+0.0128283 \times$ transcription factor AP-1 $(J U N)+0.0254552$ $\mathrm{x}$ signal transducer and activator of transcription 1 (STAT1)-0.0017589 x protein kinase $C \beta$ type-0.0038171 x transcription factor $\mathrm{p} 65+0.1070213 \mathrm{x}$ tyrosine protein kinase $A B L 1$ (ABL1)-0.0002509 x small ubiquitin-related modifier 1-0.0092431 x serinelthreonine-protein kinase PAK 2 (PAK2)-0.0204469 x histone deacetylase 1-0.0441683 x interferon regulatory factor 1 .

According to Eschrich et al (12), the lower quartile of RSI was pre-defined as the cut-off point to divide patients into radiosensitive or radioresistant groups. 
Table I. Clinical traits of oesophagus cancer with radiotherapy in The Cancer Genome Atlas database.

\begin{tabular}{|c|c|c|c|c|c|}
\hline Factors & Death/patients & $\begin{array}{l}\text { Median } \\
\text { survival time }\end{array}$ & $95 \% \mathrm{CI}$ & Log-rank & $\begin{array}{l}\text { Multivariate } \\
\text { Cox P-value }\end{array}$ \\
\hline \multicolumn{6}{|l|}{ Age } \\
\hline$\leq 60.5$ & $30 / 77$ & 1,263 & 557-NA & \multirow[t]{2}{*}{0.711} & \multirow[t]{2}{*}{0.441} \\
\hline$>60$ & $30 / 75$ & 764 & $650-\mathrm{NA}$ & & \\
\hline \multicolumn{6}{|l|}{ Sex } \\
\hline Female & $5 / 20$ & NA & $1,458-N A$ & \multirow[t]{2}{*}{0.144} & \multirow[t]{2}{*}{0.790} \\
\hline Male & $55 / 132$ & 764 & $610-1,361$ & & \\
\hline \multicolumn{6}{|l|}{ Histological type } \\
\hline $\begin{array}{l}\text { Oesophagus adenocarcinoma, } \\
\text { not otherwise specified }\end{array}$ & $34 / 75$ & 951 & 600-NA & \multirow[t]{2}{*}{0.84} & \multirow[t]{2}{*}{0.243} \\
\hline Oesophagus squamous cell carcinoma & $26 / 77$ & 764 & $567-N A$ & & \\
\hline \multicolumn{6}{|l|}{ Radiotherapy } \\
\hline Yes & $8 / 31$ & 855 & $610-1,458$ & \multirow[t]{2}{*}{0.379} & \multirow[t]{2}{*}{0.133} \\
\hline No & $52 / 121$ & 764 & 567-NA & & \\
\hline \multicolumn{6}{|l|}{ Tumour status } \\
\hline With tumour & $43 / 66$ & 600 & $484-855$ & \multirow[t]{3}{*}{0.00162} & 0.855 \\
\hline Tumour-free & $16 / 81$ & NA & $1,458-\mathrm{NA}$ & & 0.660 \\
\hline Unknown & $1 / 5$ & 730 & NA & & \\
\hline \multicolumn{6}{|l|}{ Smoking history } \\
\hline$\leq 15$ years & $13 / 29$ & 567 & 283-NA & \multirow[t]{6}{*}{0.0156} & 0.557 \\
\hline$>15$ years & $9 / 27$ & 1,402 & 730-NA & & 0.090 \\
\hline Duration not specified & $0 / 2$ & NA & NA & & 0.998 \\
\hline Current smoker & $14 / 32$ & 855 & 378-NA & & 0.356 \\
\hline Lifelong non-smoker & $9 / 45$ & NA & NA & & $0.014^{\mathrm{a}}$ \\
\hline Unknown & $15 / 17$ & 610 & $435-987$ & & \\
\hline \multicolumn{6}{|l|}{ Alcohol history } \\
\hline Yes & $37 / 107$ & 1,361 & 694-NA & \multirow[t]{3}{*}{0.249} & \\
\hline No & $23 / 48$ & 600 & 480-NA & & \\
\hline Unknown & $0 / 2$ & NA & NA & & \\
\hline \multicolumn{6}{|l|}{ TNM stage } \\
\hline Stage 0 & $1 / 1$ & 480 & NA & \multirow[t]{6}{*}{0.00045} & 0.873 \\
\hline Stage I & $5 / 19$ & 1,781 & 1402 & & $0.031^{\mathrm{a}}$ \\
\hline Stage II & $18 / 62$ & 987 & 764-NA & & 0.051 \\
\hline Stage III & $23 / 50$ & 694 & 484-NA & & 0.337 \\
\hline Stage IV & $6 / 6$ & 322 & 136-NA & & 0.958 \\
\hline Unknown & $7 / 14$ & 283 & 161-NA & & \\
\hline
\end{tabular}

${ }^{\text {a }}<<0.05$. TNM, Tumour-Node-Metastasis; NA, not applicable; CI, confidence interval.

As an evaluation criterion and a corresponding value, the area under the curve (AUC) of the receiver-operator characteristic (ROC) curve, which is applied to assess the capacity and efficiency of a gene signature for classifying patient outcome, was utilized in the present study to verify the integrated gene signature.

Prognosis index for oesophageal cancer. As an integrated indicator of gene signature for individual patients, the PI was calculated using a linear combination of the expression value of the feature genes weighted by the Cox regression coefficient.
Multivariate stepwise Cox regression was additionally used to analyse the clinical factors that were significantly associated with overall survival time by univariate survival analysis. In univariate survival analysis, $\log$-rank test $\mathrm{P}<0.05$ was considered as significance factors. The clinical variables and combination gene signature with a multivariate Cox regression significance of $\mathrm{P} \leq 0.1$ were considered as important predictors of oesophageal cancer prognosis (23), and the PI was defined as follows: $\mathrm{PI}=\beta_{1} \mathrm{X}_{1}+\beta_{2} \mathrm{X}_{2}+\ldots,+\beta_{\mathrm{i}} \mathrm{X}_{\mathrm{i}}$; where $\beta_{\mathrm{i}}$ is the Cox regression coefficient of the $i$ th variable, $X_{\mathrm{i}}$ is the value of the $i$ th variable and was the $\log _{2}$-transformed expression value of 
Table II. Radiosensitivity index (10-gene signature) for predicting radiosensitivity.

\begin{tabular}{|c|c|c|c|c|c|c|}
\hline $\begin{array}{l}\text { Gene } \\
\text { symbol }\end{array}$ & $\begin{array}{c}\text { Uniprot } \\
\text { accession no. }\end{array}$ & Description & $\begin{array}{l}\text { Univariate } \\
\text { Cox P-value }\end{array}$ & Coefficient & Hazard ratio & $95 \% \mathrm{CI}$ \\
\hline AR & P10275 & Androgen receptor & 0.078 & -1.331 & 0.264 & $0.06-1.16$ \\
\hline JUN & P05412 & Transcription factor AP-1 & 0.039 & 0.301 & 1.351 & $1.01-1.80$ \\
\hline STAT1 & P42224 & $\begin{array}{l}\text { Signal transducer and activator } \\
\text { of transcription } 1 \text {-alpha/beta }\end{array}$ & 0.622 & 0.067 & 1.069 & $0.81-1.40$ \\
\hline PRKCB & P05771 & Protein kinase $\mathrm{C}$ beta type & 0.836 & 0.031 & 1.03 & $0.76-1.40$ \\
\hline RELA & Q04206 & Transcription factor p65 & 0.501 & -0.238 & 0.789 & $0.39-1.58$ \\
\hline ABL1 & P00519 & & 0.745 & -0.102 & 0.903 & $0.49-1.67$ \\
\hline SUMO1 & P63165 & Small ubiquitin-related modifier 1 & 0.567 & 0.164 & 1.180 & $0.67-2.07$ \\
\hline PAK2 & Q13177 & Serine/threonine-protein kinase PAK 2 & 0.995 & -0.002 & 0.998 & $0.64-1.57$ \\
\hline HDAC1 & Q13547 & Histone deacetylase 1 & 0.317 & 0.266 & 1.305 & $0.77-2.20$ \\
\hline IRF1 & P10914 & Interferon regulatory factor 1 & 0.035 & 0.305 & 1.357 & $1.02-1.80$ \\
\hline
\end{tabular}

CI, confidence interval.
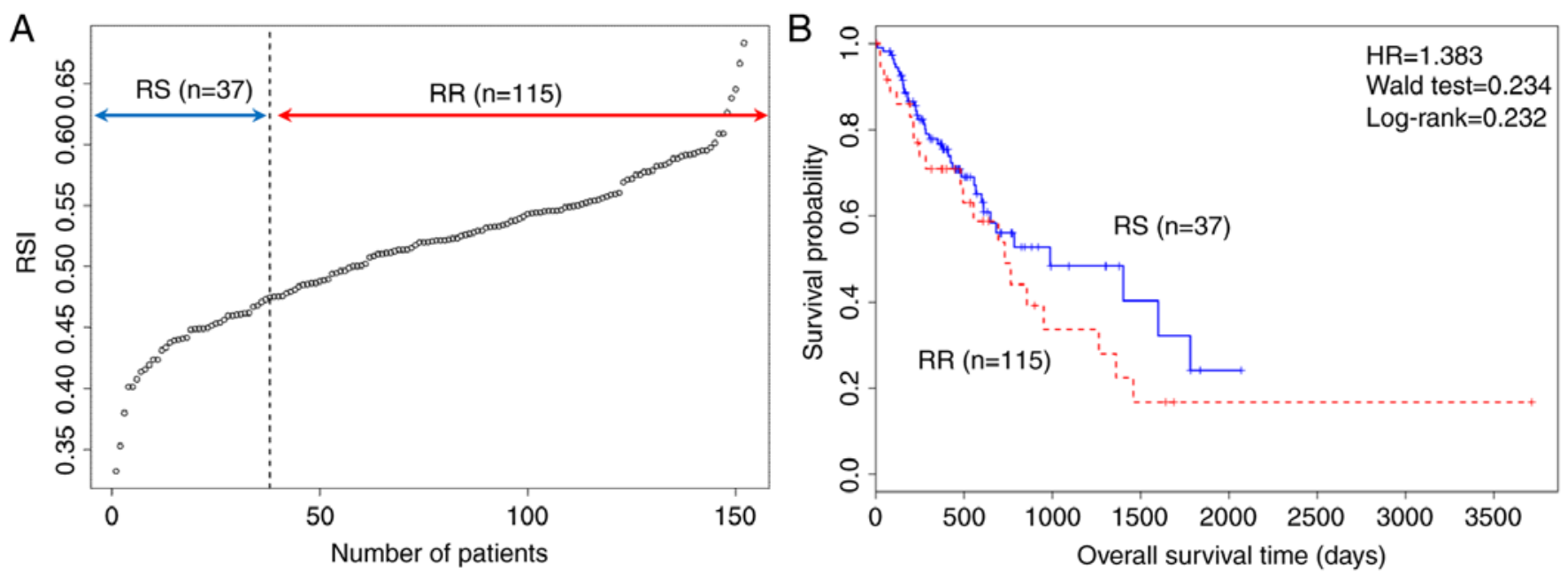

Figure 1. Standard RSI for predicting the prognosis of patients with oesophageal cancer. (A) Distribution of RSI in patients with oesophageal cancer. (B) Survival analysis comparing the RS and RR groups. $P=0.232$. RSI, radiosensitivity index; RS radiosensitive; RR, radioresistant; HR, hazard ratio.

each gene, and $\beta_{\mathrm{i}}$ was the Cox regression coefficient of the $i$ th gene.

Estimating PI with different RS gene signatures. Patients with oesophageal cancer were classified into two groups (RS and $\mathrm{RR}$ ) based on the median value of the PI (median PI value, 0.52). Kaplan-Meier curves and a two-sided log-rank test were used to compare the corresponding overall survival time and the difference in distribution of the two groups.

Gene Ontology (GO) enrichment. GO enrichment was used to analyse the functions of the genes in the 41-gene signature. Database for Annotation, Visualization and Integrated Discovery (DAVID; david.abcc.ncifcrf.gov) was used to examine the gene ontology of the selected RNAs by choosing 'Homo sapiens' and subsequently searching the terms 'GO TERM_BP_FAT', 'GO TERM_CC_FAT', and 'GO TERM_MF_FAT' for the next step in the analysis $(24,25)$.
Abbreviations are defined as follows: $\mathrm{BP}$, biological process; MF, molecular function; CC, cellular component; and FAT, function annotation chart. A Fisher's exact test was used to determine the significant categories.

Gene set enrichment analysis (GSEA). GSEA (www.broadinstitute.org/gsea) was performed using MSigDB C2 curated Kyoto Encyclopaedia of Genes and Genomes v5.2, and gene sets with a false discovery rate (FDR) value $<0.1$ after 1,000 permutations were considered to be significantly enriched (26). Additionally, GSEA was used to examine the differences in oesophageal cancer pathways between the RS and RR groups.

Programme implementation. The aforementioned univariate Cox regression, multivariate Cox regression and Kaplan-Meier survival curves for overall survival were analysed using R (version 3.2.4; www.R-project.org) (27) with R studio (version 1.1.463) (28) and the 'survival' package (5). 
Table III. A 31-gene signature for predicting radiosensitivity.

\begin{tabular}{|c|c|c|c|c|c|c|}
\hline $\begin{array}{l}\text { Gene } \\
\text { symbol }\end{array}$ & $\begin{array}{l}\text { Uniprot } \\
\text { accession no. }\end{array}$ & Description & $\begin{array}{l}\text { Univariate } \\
\text { Cox P-value }\end{array}$ & Coefficient & $\begin{array}{l}\text { Hazard } \\
\text { ratio }\end{array}$ & $95 \% \mathrm{CI}$ \\
\hline ACTN1 & P12814 & Alpha-actinin-1 & 0.746 & -0.054 & 0.947 & $0.68-1.31$ \\
\hline ANXA2 & P07355 & Annexin A2 & 0.102 & -0.299 & 0.741 & $0.52-1.06$ \\
\hline ANXA5 & P14668 & Annexin A5 & 0.588 & -0.097 & 0.907 & $0.64-1.29$ \\
\hline ARHGDIB & P52566 & Rho GDP-dissociation inhibitor 2 & 0.285 & 0.136 & 1.145 & $0.89-1.47$ \\
\hline CAPNS1 & P04632 & Calpain small subunit 1 & 0.629 & 0.138 & 1.148 & $0.66-2.01$ \\
\hline CBR1 & P16152 & Carbonyl reductase [NADPH] 1 & 0.791 & 0.031 & 1.032 & $0.82-1.30$ \\
\hline CCND1 & P24385 & G1/S-specific cyclin-D1 & 0.900 & 0.012 & 1.012 & $0.84-1.22$ \\
\hline CD63 & P08962 & CD63 antigen & 0.687 & 0.075 & 1.077 & $0.75-1.55$ \\
\hline CORO1A & P31146 & Coronin-1A & 0.248 & 0.141 & 1.152 & $0.91-1.46$ \\
\hline CXCR4 & P61073 & C-X-C chemokine receptor type 4 & 0.756 & -0.029 & 0.971 & $0.81-1.17$ \\
\hline DAG1 & Q14118 & Dystroglycan & 0.197 & -0.200 & 0.818 & $0.60-1.11$ \\
\hline EMP2 & P54851 & Epithelial membrane protein 2 & 0.983 & 0.003 & 1.003 & $0.76-1.31$ \\
\hline HCLS1 & P14317 & Hematopoietic lineage cell-specific protein & 0.088 & 0.187 & 1.206 & $0.97-1.49$ \\
\hline HTRA1 & Q92743 & Serine protease HTRA1 & 0.210 & 0.163 & 1.177 & $0.91-1.52$ \\
\hline ITGB5 & P18084 & Integrin beta-5 & 0.874 & -0.032 & 0.969 & $0.65-1.43$ \\
\hline LAPTM5 & Q13571 & $\begin{array}{l}\text { Lysosomal-associated transmembrane } 5 \\
\text { protein }\end{array}$ & 0.121 & 0.152 & 1.164 & $0.96-1.41$ \\
\hline LRMP & Q12912 & Lymphoid-restricted membrane protein & 0.553 & 0.086 & 1.089 & $0.82-1.45$ \\
\hline MYB & P10242 & Transcriptional activator Myb & 0.932 & -0.008 & 0.992 & $0.82-1.02$ \\
\hline PFN2 & P35080 & Profilin-2 & 0.518 & 0.056 & 1.058 & $0.89-1.25$ \\
\hline PIR & O00625 & Pirin & 0.043 & 0.237 & 1.268 & $1.01-1.59$ \\
\hline PKM2 & P14618 & Pyruvate kinase PKM & 0.985 & 0.003 & 1.003 & $0.70-1.43$ \\
\hline PTMS & P04550 & Parathymosin & 0.290 & 0.176 & 1.192 & $0.86-1.65$ \\
\hline PTPRC & P08575 & $\begin{array}{l}\text { Receptor-type tyrosine-protein } \\
\text { phosphatase C }\end{array}$ & 0.350 & 0.096 & 1.100 & $0.90-1.34$ \\
\hline PTPRCAP & Q14761 & Protein tyrosine phosphatase receptor & 0.435 & 0.085 & 1.089 & $0.88-1.35$ \\
\hline PYGB & P11216 & $\begin{array}{l}\text { Glycogen phosphorylase, brain form } \\
\text { type C-associated protein }\end{array}$ & 0.622 & -0.063 & 0.939 & $0.73-1.21$ \\
\hline RAB13 & P51153 & Ras-related protein Rab-13 & 0.965 & 0.012 & 1.012 & $0.59-1.72$ \\
\hline RALB & P11234 & Ras-related protein Ral-B & 0.724 & -0.077 & 0.926 & $0.60-1.42$ \\
\hline SCRN1 & Q12765 & Secernin-1 & 0.683 & 0.060 & 1.062 & $0.80-1.42$ \\
\hline SQSTM1 & Q13501 & Sequestosome-1 & 0.218 & 0.197 & 1.218 & $0.89-1.67$ \\
\hline TWF1 & Q12792 & Twinfilin-1 & 0.277 & 0.282 & 1.325 & $0.79-2.20$ \\
\hline WAS & P42768 & Wiskott-Aldrich syndrome protein & 0.246 & 0.137 & 1.147 & $0.91-1.45$ \\
\hline
\end{tabular}

CI, confidence interval.

The ROC curve was plotted using the 'survival ROC' package (29). Log-rank test is used to test the significance of Kaplan-Meier curve (23) and Wald test is used to test Cox regression (30).

\section{Results}

Clinical characteristics of patients with oesophageal cancer. The clinical data of oesophageal cancer patients in TCGA are summarized in Table I. In total, eight clinical factors (age, sex, histological type, radiotherapy, tumour status, smoking history, alcohol history and TNM stage) were used for survival analysis.
In the present study, seven variables (age, gender, histological type, tumour status, smoking history, alcohol history and TNM stage) were tested for their association with survival. Table I demonstrates that tumour status, smoking history and TNM stage were significantly associated with overall survival in patients with oesophageal cancer in univariate survival analysis (log-rank test, $\mathrm{P}<0.05)$. Multivariate Cox regression analysis of these factors suggested TNM stage was correlated with overall survival time, and TNM stage I was closely associated with survival time (Table I). There was no significant difference in TCGA between oesophageal cancer patients treated with and without radiotherapy, and fewer patients received radiotherapy. 
Table IV. Genes determined to be significant based on univariate Cox regression of the combined 41-gene signature.

\begin{tabular}{lclcrrr}
\hline $\begin{array}{l}\text { Gene } \\
\text { symbol }\end{array}$ & $\begin{array}{c}\text { Uniprot } \\
\text { accession no. }\end{array}$ & \multicolumn{1}{c}{ Description } & $\begin{array}{c}\text { Multivariate } \\
\text { cox P-value }\end{array}$ & Coefficient & Hazard ratio & 95\% CI \\
\hline ANXA5 & P14668 & Annexin A5 & 0.068 & -0.688 & 0.526 & $0.24-1.05$ \\
TWF1 & Q12792 & Twinfilin-1 & 0.074 & 0.832 & 2.299 & $0.92-5.73$ \\
AR & P10275 & Androgen receptor & 0.009 & -4.625 & 0.010 & $0.00-0.31$ \\
JUN & P05412 & Transcription factor AP-1 & 0.093 & 0.387 & 1.472 & $0.94-2.31$ \\
STAT1 & P42224 & Signal transducer and activator & 0.041 & -0.646 & 0.515 & $0.27-0.97$ \\
IRF1 & P10914 & Interferon regulatory factor 1 & 0.011 & 0.878 & 2.405 & $1.22-4.74$ \\
\hline CI, confidence interval. & & & & & & \\
\hline
\end{tabular}

Table V. Cox regression analysis of prognosis index of all the different of gene signatures.

\begin{tabular}{lcccc}
\hline PI in Type of radiosensitivity genes & Number of genes & HR & $95 \%$ CI & P-value \\
\hline Standard RSI & 10 & 1.383 & $0.810-2.362$ & 0.232 \\
PI of RSI & 10 & 2.218 & $1.307-3.764$ & 0.003 \\
31-gene signature & 31 & 2.402 & $1.410-4.093$ & 0.001 \\
RSI+31-gene signature & 41 & 2.967 & $1.717-5.127$ & $9.71 \times 10^{-5}$ \\
Multivariate Cox screen & 6 & 0.6380 & $0.380-1.070$ & 0.089 \\
\hline
\end{tabular}

PI, prognostic index; HR, hazard ratio; CI, confidence interval; RSI, radiodensity index.

Standard RSI for estimating RS and RR groups. The RSI was calculated in 152 patients with oesophageal cancer, classifying patients into two groups (RS, 25\%; RR, 75\%) and the cut off point for classification was 0.474 . The overall survival of the two groups using a Kaplan-Meier plot is presented in Fig. 1, and the plot suggested that standard RSI was not able to satisfactorily predict overall survival of patients with oesophageal cancer.

Gene signature for predicting prognosis in TCGA oesophageal cancer cohort. Considering that the RSI did not predict overall survival, the PI of two independent gene signatures and their integration was calculated and analysed. First, the ten genes from RSI were used to perform univariate Cox regression (Table II). Subsequently, the 31-gene signature combination was analysed by univariate Cox regression in addition to the former analysis (Table III). The present study proposed that these genes may be biomarkers for predicting RR and RS in several cell lines. In the current study, Jun proto-oncogene, AP-1 transcription factor subunit (JUN), interferon regulatory factor 1 (IRF1) and pirin (PIR) were significantly associated with survival in oesophageal cancer $(\mathrm{P}<0.05$; Tables II and III). Of the three genes, JUN is closely associated with tumour development (29) and IRF1 is a radioresistance biomarker (28). The gene PIR has rarely been reported to be associated with oesophageal cancer. PIR may act as a redox sensor for the nuclear factor $\kappa \beta$ and is involved in stress responses (30). The present study revealed that not all genes associated with survival in oesophageal cancer $(\mathrm{P}>0.05)$. Therefore, two gene signatures for predicting RS and RR for oesophageal cancer were proposed. To identify the core genes for predicting prognosis, multivariate Cox regression was used to filter combination genes (41 genes), obtaining six genes with a $\mathrm{P}<0.1$ as a cut-off threshold (Table IV). However, analysis of the core genes demonstrated that their combination was not significantly associated with overall survival time (HR, 0.638; 95\% CI; 0.380-1.070; $\mathrm{P}=0.089$; Wald test; Table V). To separate the patients into RS and RR, the median value of PI was selected (Fig. 2).

As a linear combination of the expression values of 10 genes, the PI of RSI, calculated by the aforementioned formula, was significantly relevant with overall survival time (HR, 2.218, 95\% CI, 1.307-3.764; $\mathrm{P}=0.0025$, Wald test; Table V). The PI of the 31-gene signature was also significantly associated with overall survival time (HR, 2.402; 95\% CI, 1.410-4.093; $\mathrm{P}=0.001$; Wald test; Table V). The RSI and the 31-gene signature were combined and the aforementioned process was used to calculate the PI. The results demonstrated that the PI of the combination was more significantly associated with overall survival time compared with RSI or the 31-gene signature alone (HR, 2.967; 95\% CI, 1.717-5.127; P=4.66×10-5; Wald test; Table V). As demonstrated in the survival analysis and Fig. 2, the RS group had an improved prognosis compared with the RR group, particularly when considering the effect of the combination of RSI and the 31-gene signature, which had the highest $\mathrm{HR}$ and the most significant P-value. Therefore, the 41-gene signature may be the best biomarker for classifying patients with oesophageal cancer into RS or RR groups.

Gene signature validation in patients who had received radiotherapy. For further validation of the effectiveness and 

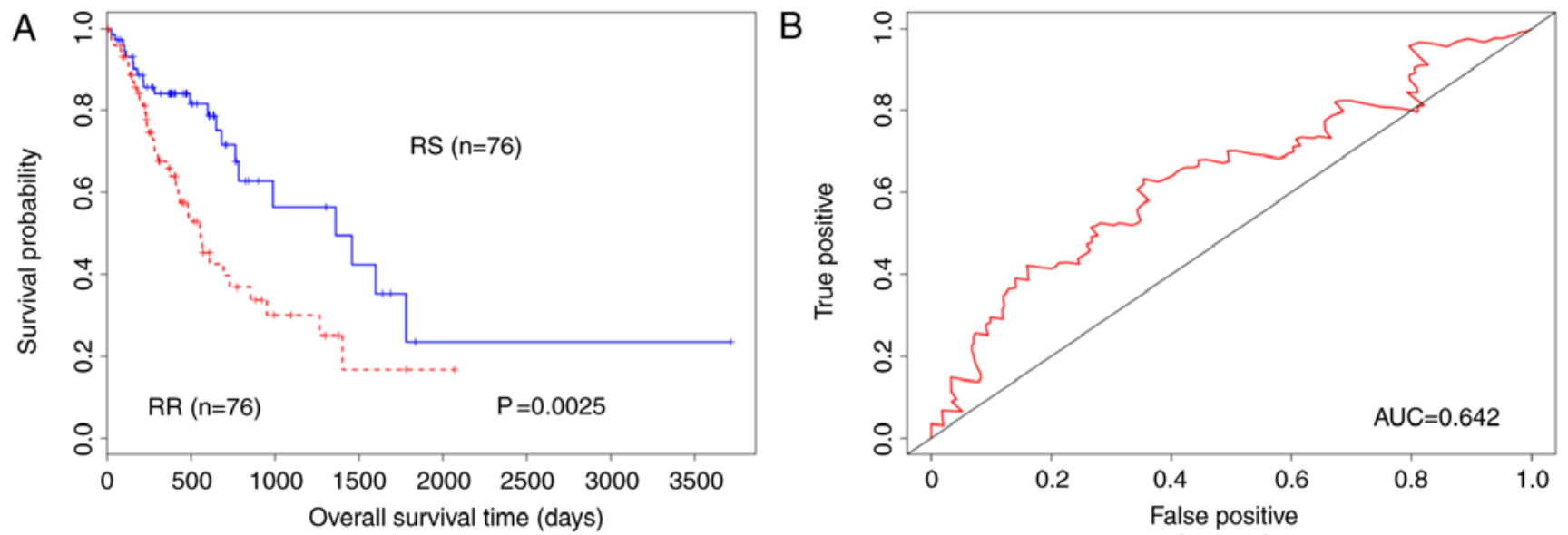

(3 years)
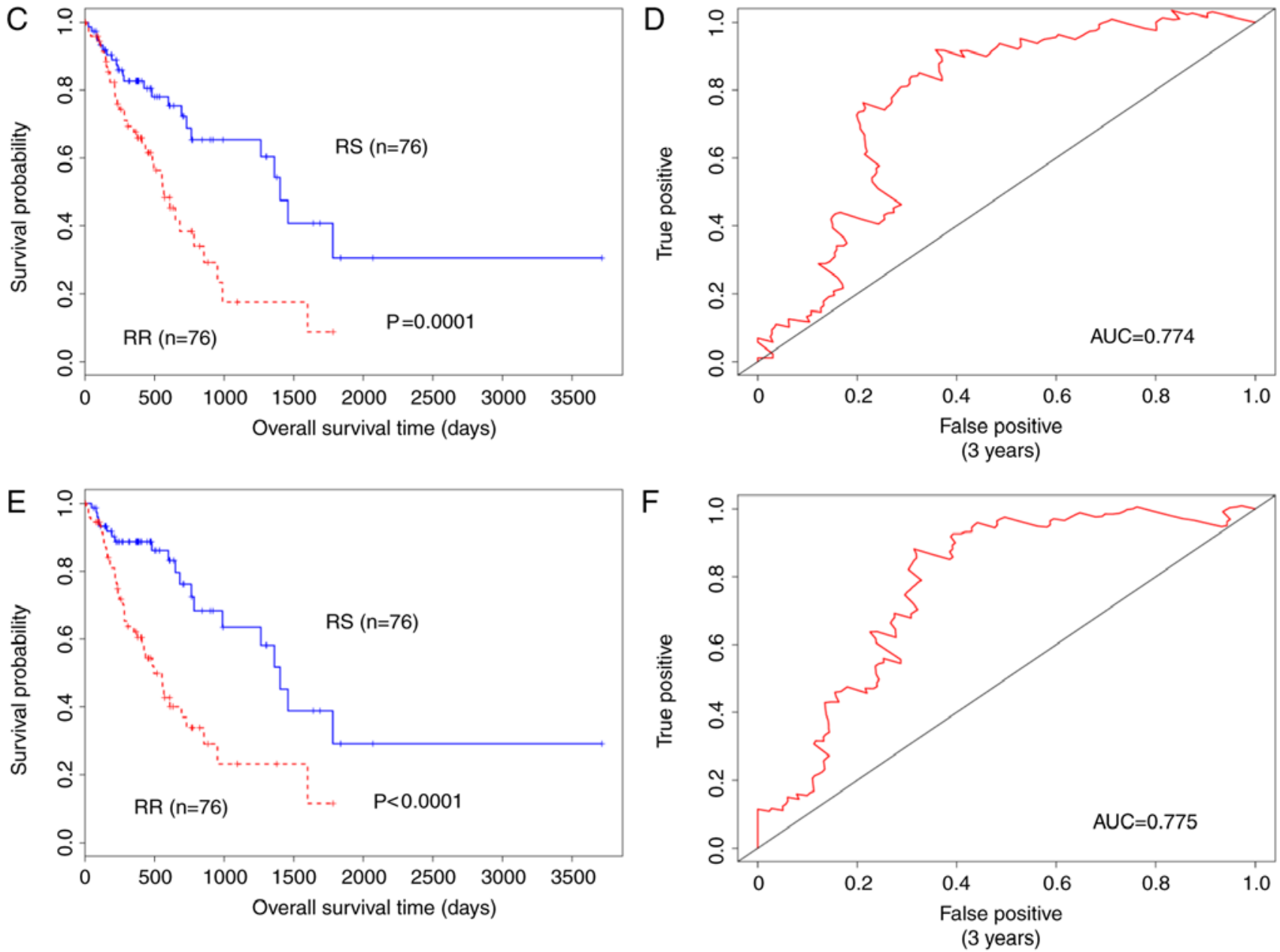

Figure 2. Survival analysis and ROC curve for estimating the radiosensitivity gene signature effect in the prognosis of oesophageal cancer patients. (A) Survival curve of the 10-gene signature PI in TCGA oesophageal cancer patients. (B) ROC curve of the 10-gene signature PI. (C) Survival curve of the 31-gene signature PI in TCGA oesophageal cancer patients. (D) ROC curve of the 31-gene signature. (E) Survival curve of the combination genes (41-gene signature) PI in TCGA oesophageal cancer patients. (F) ROC curve of the 41-gene signature PI. ROC, receiver operator characteristic; PI, prognostic index; TCGA, The Cancer Genome Atlas; RS, radiosensitive; RR, radioresistant; AUC, area under the curve.

performance of the two independent gene signature and combination models, samples from 31 patients who had received radiotherapy were selected for assessment (Fig. 3).

Additionally, with the TNM staging system being an important clinical indicator for tumours in clinical practice, in the present study, the 41-gene signature was used to predict the outcome of all stages of patients with oesophageal cancer
(Fig. 4). The results demonstrated that the 41-gene signature of RS classified all stages significantly, with an improved predictive capacity for Stage II and Stage III.

Core genes for patients who have received radiotherapy. The results demonstrated that the core genes were not able to predict RS and RR groups in all patients with oesophageal 

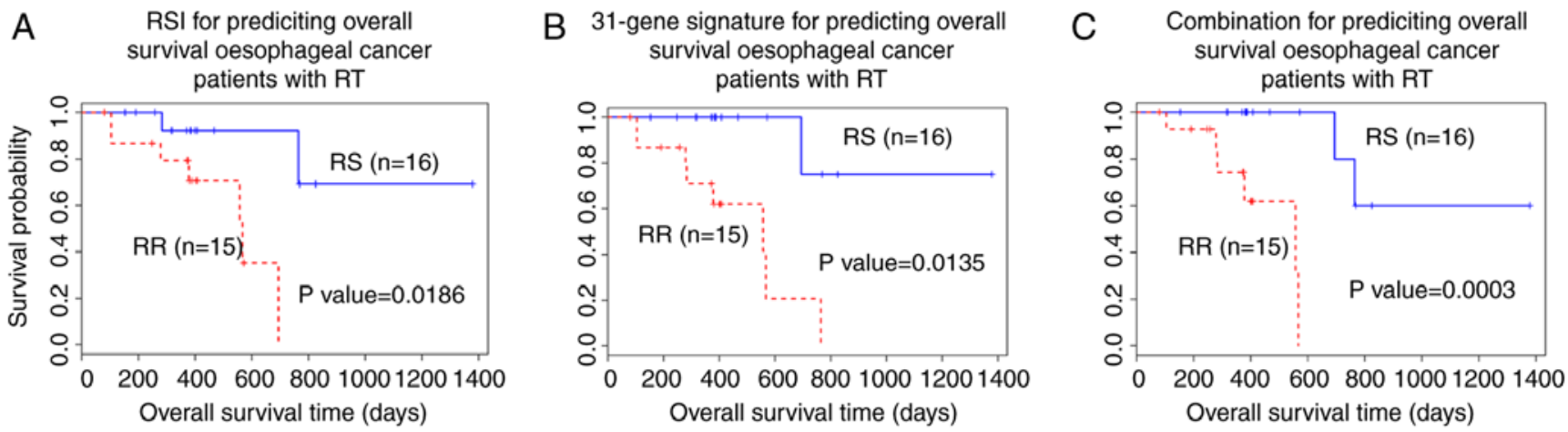

Figure 3. Comparison of the two independent gene signature models for predicting RS and RR in patients with oesophageal cancer. (A) RSI (10-gene signature combination) for predicting overall survival of patients with oesophageal cancer. Kaplan-Meier curves for the RS and RR groups separated by the RSI of the gene signature in the oesophageal cancer cohort. $\mathrm{P}=0.0186$. (B) A 31-gene signature for predicting the overall survival of patients with oesophageal cancer. Kaplan-Meier curves for the RS and RR groups separated by the 31-gene signature in the oesophageal cancer cohort. $\mathrm{P}=0.0135$. (C) Combination of the gene signatures for predicting overall survival of oesophageal cancer patients. Kaplan-Meier curves for the RS and RR groups separated by combination gene signature in the oesophageal cancer cohort. $\mathrm{P}=0.0003$. RS, radiosensitive; RR, radioresistant; RSI, radiosensitive index; RT, radiotherapy.

A

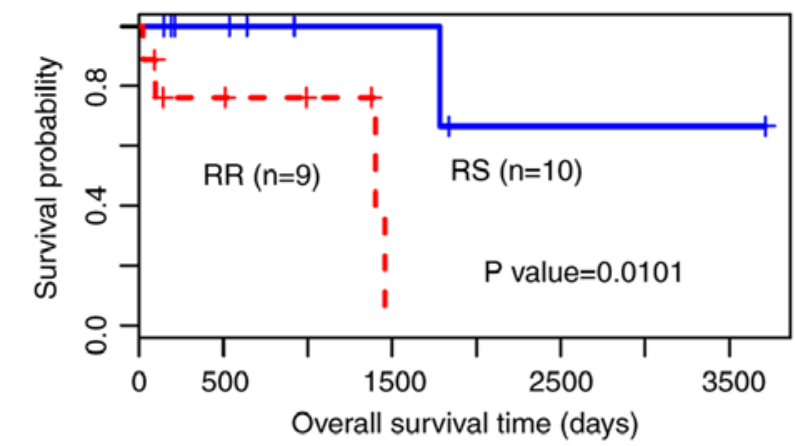

C

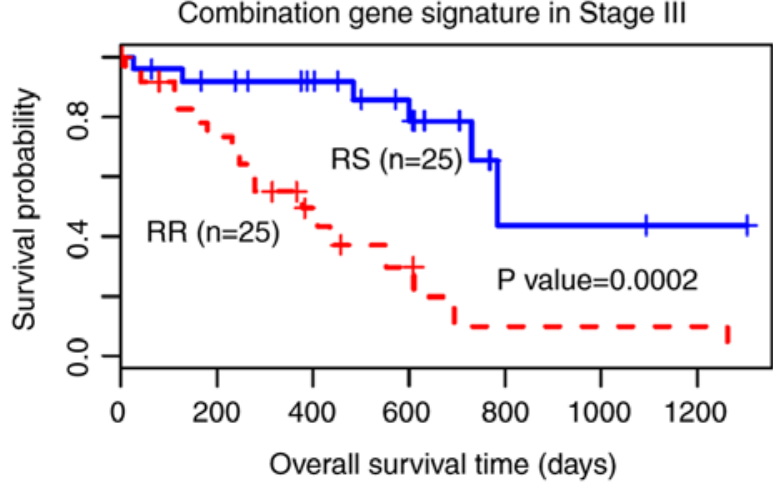

B

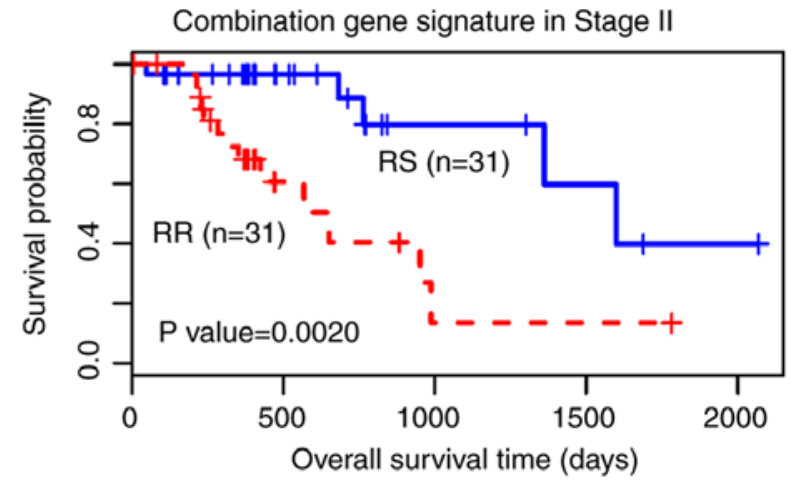

D

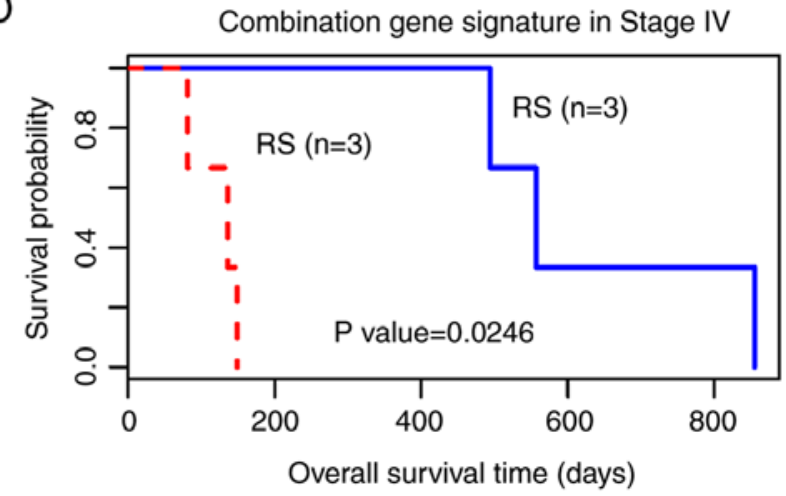

Figure 4. Combined 41-gene signature classifying the RS and RR groups by Tumor-Node-Metastasis stage of oesophageal cancer. The 41-gene signaturesignificantly classifiedoesophageal cancer patients into RS and RR groups in all stages by log-rank test. (A) Stage I. P=0.0101. (B) Stage II. P=0.0020. (C) Stage III. $\mathrm{P}=0.0002$. (D) Stage IV. $\mathrm{P}=0.0246$. $\mathrm{RS}$, radiosensitive; $\mathrm{RR}$, radioresistant.

cancer (Table V). Therefore, the core genes were tested in patients who received radiotherapy $(n=31)$. The 41 -gene signature combination performed well in predicting the prognosis in all oesophageal cancer patients and patients who had received radiotherapy. Multivariate Cox regression analysis demonstrated that the core genes [CBR $1, P A K 2$, ras-related protein Rab 13 (RAB13) and twinfilin-1(TWF1)] may significantly predict the prognosis of patients with oesophageal cancer who had received radiotherapy (Fig. 5).

The results demonstrated that the expression of the four core genes differed between the RS and RR groups (Fig. 5A).
The RS group had a significantly longer survival time compared with the RR group ( $\mathrm{P}=0.0003$; Fig. 5).

GO enrichment. The results indicated that the 41-gene signature combination had the highest HR and the largest significant difference between the RS and RR groups. Therefore, the GO terms associated with these 41 genes were analysed, and the results (top 10 catalogues) are presented in Fig. 6. The 41 genes were primarily associated with protein phosphorylation and protein binding (Fig. 6A and B). These genes were mainly enriched in the 'cytosol' and 'extracellular exosome' (Fig. 6C). 

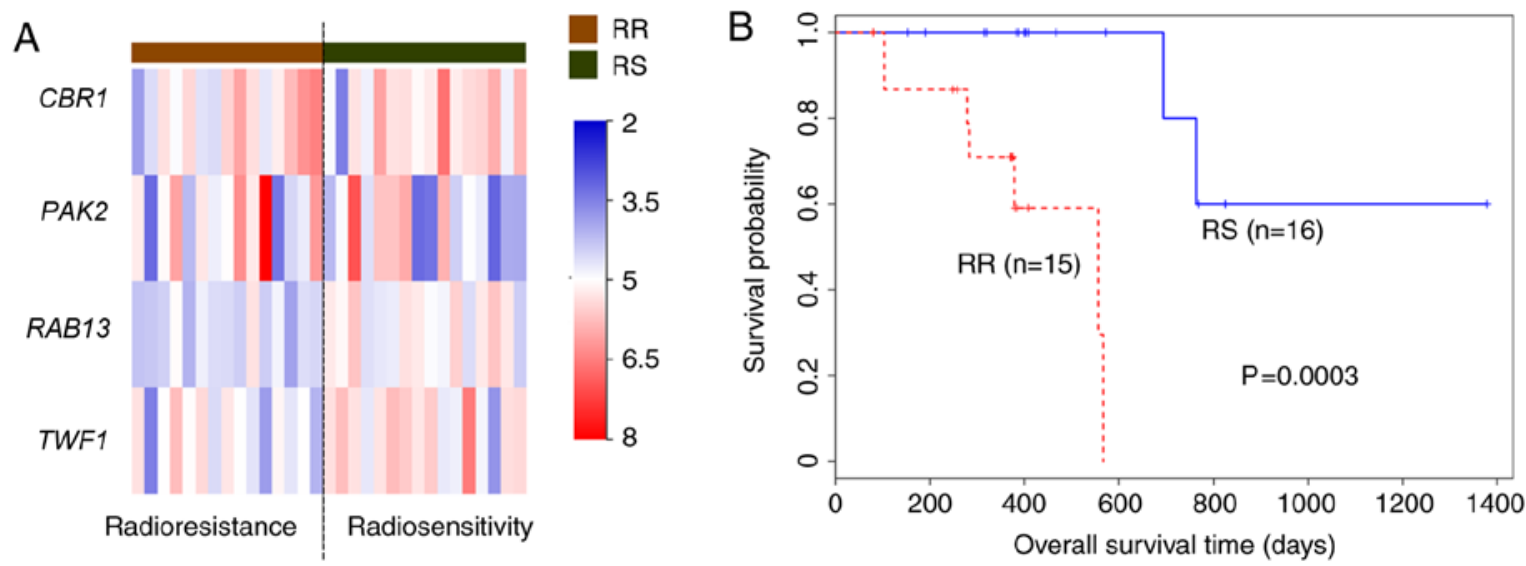

Figure 5. Core genes identified by multivariate Cox regression analysis on the 41-gene combination. (A) Heat mapdepicting the expression of the core genes in RR and RS patients. (B) Kaplan-Meier curves for the RS and RR groups separated by the core genes combination in the oesophageal cancer cohort ( $\mathrm{P}=0.0003)$. RS, radiosensitive; RR, radioresistant; CBR1, carbonyl reductase 1; PAK2, serine/threonine-protein kinase PAK 2; RAB13, ras-related protein Rab 13; TWF1, twinfilin 1.

A

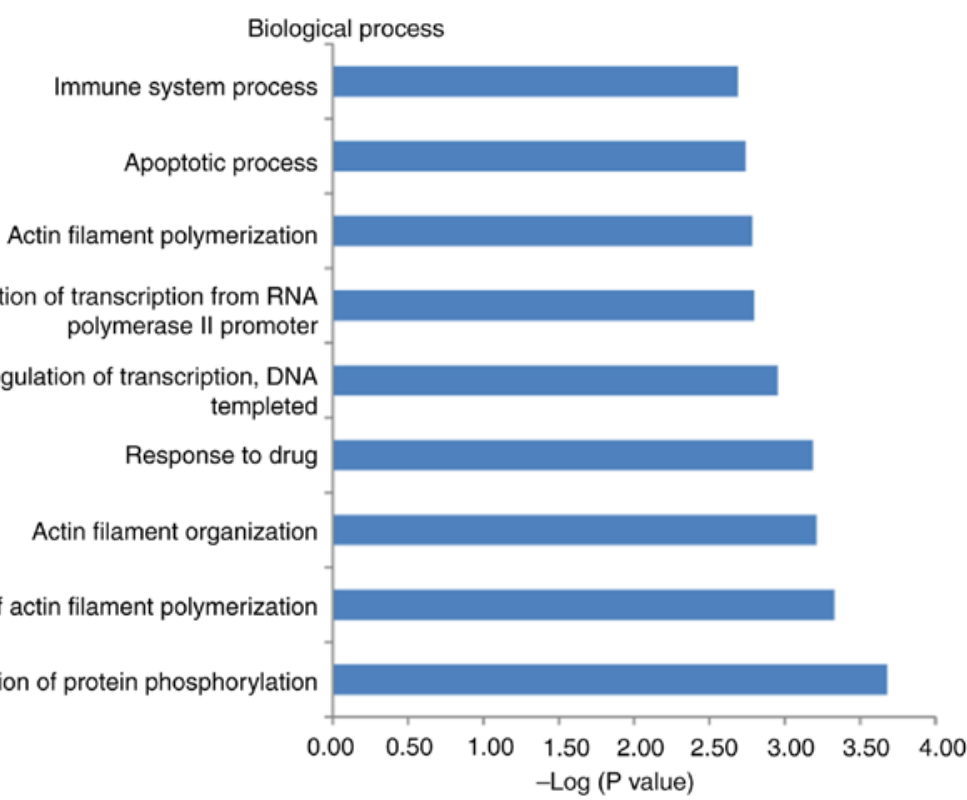

B

Molecular function

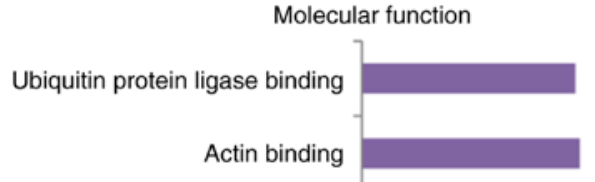

Transcriptional activator activity, RNA polymerase II core promoter proximal region sequence-specific..

Protein complex binding

Transcription factor binding

RNA polymerase II core promoter proximal region sequence-specific DNA binding

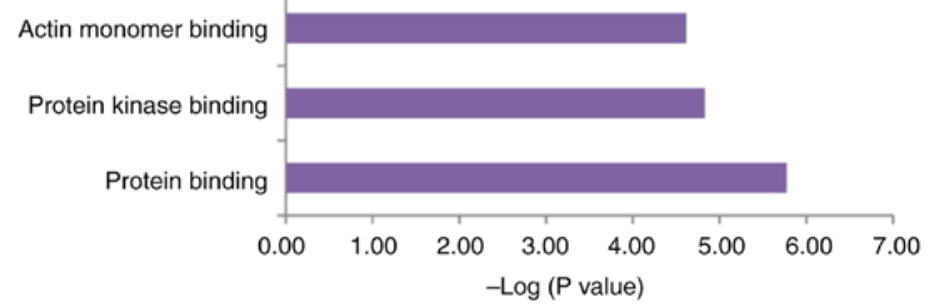

Figure 6. Gene Ontology enrichment in 41-gene signature. Gene Ontology enrichment in (A) biological process and (B) molecular function. 


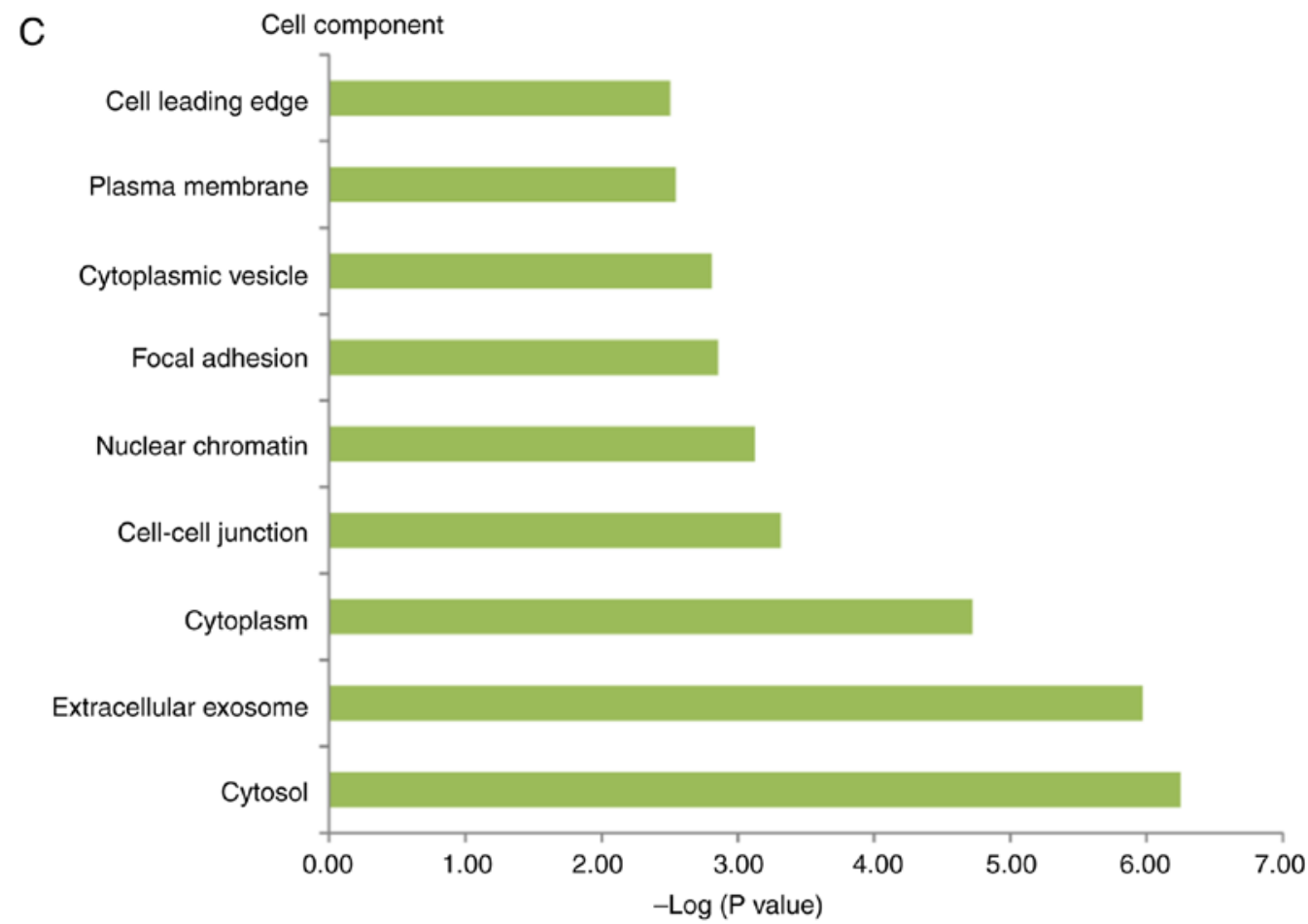

Figure 6. Continued. Gene Ontology enrichment in 41-gene signature. Gene Ontology enrichment in (C) cell component.
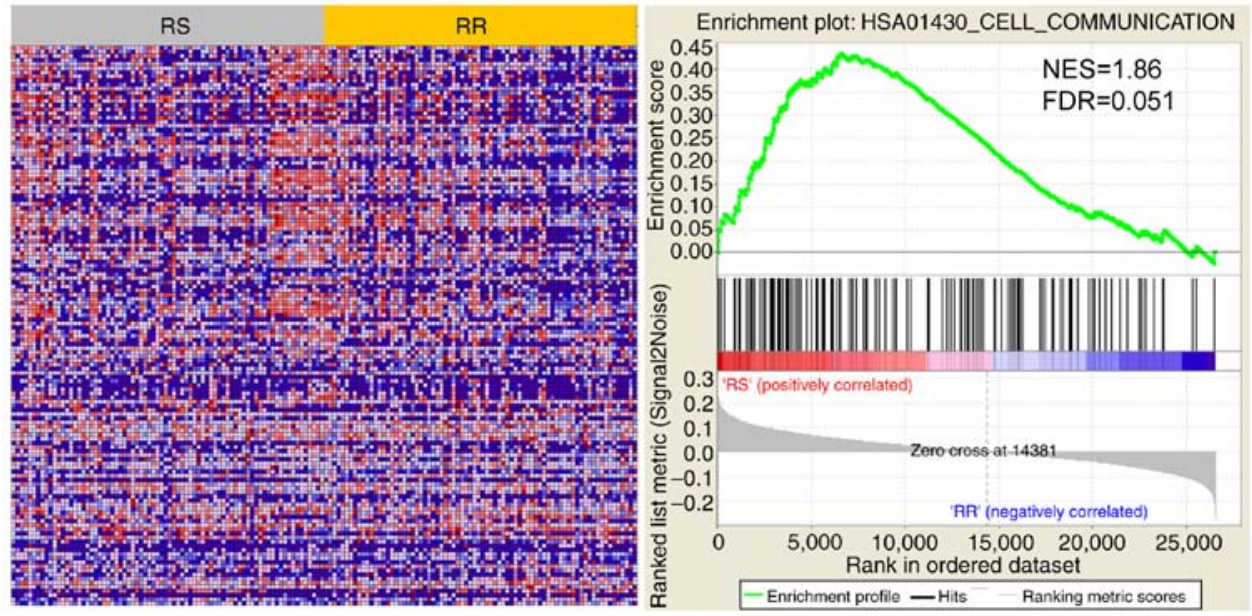

Figure 7. Gene set enrichment analysis demonstrates enrichment of the cell communication pathway classified by the 41-gene signature. RS, radiosensitive; $\mathrm{RR}$, radioresistant; NES, normalized enrichment score; FDR, false discovery rate.

The results indicated that radiosensitivity and radioresistance were closely associated with these cellular components.

Identification of the 'cell communication' pathway by GSEA. The RS and RR groups were divided by the 41-gene signature to analyse the active pathway. The results demonstrated that 'cell communication' was significantly different between the RS and RR groups (Fig. 7). Using GSEA analysis, the normalized enrichment score was 1.86, and the FDR was 0.051 .

\section{Discussion}

In the present study, the results suggested that integrating the two previously developed radiosensitive gene signatures $(6,7)$ demonstrated improved performance in predicting overall survival in patients with oesophageal cancer compared with either method alone. RSI and the 31-gene signature were independently proposed, and the two signatures are related to SF2 measured from cellular radiosensitivity. The two types of gene signatures predicted clinical outcomes using univariate Cox regression analysis, and the 31-gene signature performed better compared with RSI. When the two types of gene signatures were combined, the combination (41-gene) signature demonstrated the highest HR and most significant P-value. However, when multivariate Cox regression analysis was used to screen independent genes for prognosis, the novel gene combination of 6 genes did not predict survival; demonstrating that the expression of 
the 41 genes was associated with overall survival in patients with oesophageal cancer.

Compared with the previous studies on the radiosensitivity of oesophageal cancer, a common radiosensitive gene signature to predict overall survival instead of gene expression differences in cell lines was applied. For example, cyclin-dependent kinase inhibitor $2 A$, interferon- $\beta 1$, matrix metalloproteinase 1, protein S100-A4, andtumor necrosis factor receptor superfamily member 25 were demonstrated to be upregulated, whereas granzyme A, Myc proto-oncogene, transforming growth factor $\beta 1$ and tumor necrosis factor- $\alpha$ were downregulated (RS vs. RR cell lines) (31). In clinical practice, clinicians cannot make a distinction between whether patients are RS or RR a priori. In addition, different RS and RS oesophageal cancer cell lines express different biomarkers and regulation levels from 13 oesophageal cancer cell lines analysis (32). Therefore, there is no universal gene group to determine radiosensitivity. A previous study indicated that $C A B P R$, fatty acid binding protein 5, desmocollin-2, glutathione peroxidase 2 , thioredoxin domain-containing protein, carbonyl reductase $(C B R) 3$, dedicator of cytokinesis 8 , and multidrug resistance-associated protein 1 were upregulated, whereas replication protein A $70 \mathrm{kDa}$ DNA-binding subunit, leucine zipper protein down-regulated in cancer cells, necdin, and the $S$-phase kinase-associated protein 1 were downregulated (32). It has been hypothesized that genes coding for proteins involved in the cell cycle and DNA repair are associated with radiosensitivity (33-35). Furthermore, a number of RS genes derived from cell lines present a significant obstacle in clinical practice as several different markers may confound clinical decision-making. Although the gene signatures used were selected from cell lines, these gene signatures were validated using a large amount of clinical data.

As radiosensitivity is difficult to study at the molecular level, RS genes are simply obtained from cellular experiments using SF2. Although a number of studies have predicted specific radiosensitive biomarkers for a limited number of cancer types $(36,37)$, only a small number of common biomarkers for prognosis have been identified $(22,38)$. The function of the 41-gene signature was investigated using GO. The 41 genes were primarily involved in protein phosphorylation biological processes. In particular, protein phosphorylation is closely associated with radiosensitivity $(39,40)$. Based on the molecular function and cellular component analysis, these genes may primarily serve protein-binding functions and are located in the cytosol. Additionally, the majority of these genes (STAT1, AR, JUN, $P I R$ and $A B L 1$ ) serve vital roles in transcriptional regulation. The expression of transcription factors as indicators may predict radiosensitivity in cancer cells. Consequently, RS and RR groups that were classified using the 41-gene signature from GSEA were analysed, and it was demonstrated that the cell communication pathway was active in the RS group, consistent with the conclusions related to drug sensitivity in a recent study (41). However, the association between cell communication and radiosensitivity has not been studied, to the best of our knowledge.

Additionally, the four core genes $(C B R 1, P A K 2, R A B 13$ and $T W F 1)$ were sufficient for predicting the prognosis of patients with radiotherapy. One gene ( $P A K 2)$ was derived from RSI and the other three genes $(C B R 1, R A B 13$ and $T W F 1)$ were derived from the 31-gene signature. Common radiosensitivity genes were used to obtain specific special biomarkers for predicting RS and RR groups in patients with oesophageal cancer. The biomarkers from clinical data may be more useful than those from experiments with cell lines in clinical practice.

The current study had several limitations. While the relevance of specific genes for the effective prognosis prediction of oesophageal cancer was demonstrated in the current study, a limited sample size was investigated. Future clinical validation using larger sample sizes is warranted. The present study did not attempt to predict the relapse free survival (RFS) rate, as information on RFS was incomplete. However, the integrated 41-gene signature is an optimal radiosensitivity candidate for predicting the overall survival of oesophageal cancer.

\section{Acknowledgements}

Not applicable.

\section{Funding}

The present study was supported by a Gansu Province Science Foundation (grant no. 1606RJZA016).

\section{Availability of data and materials}

The datasets generated and/or analyzed during the current study are available in the Cancer Genome Atlas repository (https://xenabrowser.net/datapages/?cohort=GDC\%20TCGA\%20 Esophageal\%20Cancer\%20(ESCA)\&removeHub=https $\% 3 \mathrm{~A}$ $\% 2 \mathrm{~F} \% 2$ Fxena.treehouse.gi.ucsc.edu\%3A443).

\section{Authors' contribution}

QNZ and ZTB performed the analysis and wrote the manuscript. JHT was another major contributor in interpreting the biological and clinical data and writing the manuscript. XHW proposed and designed the methods for this manuscript. RFL and YL preprocessed the downloaded data. YRK and YY performed statistical analysis and validation. All authors read and approved the final manuscript.

\section{Ethics approval and consent to participate}

Not applicable.

\section{Patient consent for publication}

Not applicable.

\section{Competing interests}

The authors declare that they have no competing interests.

\section{References}

1. Siegel RL, Miller KD and Jemal A: Cancer statistics, 2016. CA Cancer J Clin 66: 7-30, 2016. 
2. Chen W, Zheng R, Baade PD, Zhang S, Zeng H, Bray F, Jemal A, Yu XQ and He J: Cancer statistics in China, 2015. CA Cancer J Clin 66: 115-132, 2016

3. $\mathrm{Ng} \mathrm{J}$ and Lee P: The role of radiotherapy in localized esophageal and gastric cancer. Hematol Oncol Clin North Am 31: 453-468, 2017.

4. Ravi S, Khaldoun A, Meredith KL, Biagioli MC, Chuong MD, Cruz A and Hoffe SE: Radiation therapy and esophageal cancer. Cancer Control 20: 97-110, 2013

5. Altorki $\mathrm{N}$ and Harrison S: What is the role of neoadjuvant chemotherapy, radiation, and adjuvant treatment in resectable esophageal cancer? Ann Cardiothorac Surg 6: 167-174, 2017.

6. Scott JG, Berglund A, Schell MJ, Mihaylov I, Fulp WJ, Yue B, Welsh E, Caudell JJ, Ahmed K, Strom TS, et al: A genome-based model for adjusting radiotherapy dose (GARD): A retrospective, cohort-based study. Lancet Oncol 18: 202-211, 2017.

7. Begg AC: Predicting response to radiotherapy: Evolutions and revolutions. Int J Radiat Biol 85: 825-836, 2009.

8. Amundson SA, Do KT, Vinikoor LC, Lee RA, Koch-Paiz CA Ahn J, Reimers M, Chen Y, Scudiero DA, Weinstein JN, et al: Integrating global gene expression and radiation survival parameters across the 60 cell lines of the national cancer institute anticancer drug screen. Cancer Res 68: 415-424, 2008.

9. Lynam-Lennon N, Reynolds JV, Marignol L, Sheils OM Pidgeon GP and Maher SG: MicroRNA-31 modulates tumour sensitivity to radiation in oesophageal adenocarcinoma. J Mol Med (Berl) 90: 1449-1458, 2012.

10. Chen GZ, Zhu HC, Dai WS, Zeng XN, Luo JH and Sun XC: The mechanisms of radioresistance in esophageal squamous cell carcinoma and current strategies in radiosensitivity. $\mathrm{J}$ Thorac Dis 9: 849-859, 2017.

11. Fukuda K, Sakakura C, Miyagawa K, Kuriu Y, Kin S, Nakase Y, Hagiwara A, Mitsufuji S, Okazaki Y, Hayashizaki Y and Yamagishi H: Differential gene expression profiles of radioresistant oesophageal cancer cell lines established by continuous fractionated irradiation. Br J Cancer 91: 1543-1550, 2004.

12. Eschrich S, Zhang H, Zhao H, Boulware D, Lee JH, Bloom G and Torres-Roca JF: Systems biology modeling of the radiation sensitivity network: A biomarker discovery platform. Int J Radiat Oncol Biol Phys 75: 497-505, 2009.

13. Kim HS, Kim SC, Kim SJ, Park CH, Jeung HC, Kim YB, Ahn JB, Chung HC and Rha SY: Identification of a radiosensitivity signature using integrative metaanalysis of published microarray data for NCI-60 cancer cells. BMC Genomics 13: 348, 2012.

14. Eschrich SA, Fulp WJ, Pawitan Y, Foekens JA, Smid M, Martens JW, Echevarria M, Kamath V, Lee JH, Harris EE, et al Validation of a radiosensitivity molecular signature in breast cancer. Clin Cancer Res 18: 5134-5143, 2012.

15. Torres-Roca JF, Erho N, Vergara I, Davicioni E, Jenkins RB, Den RB, Dicker AP and Eschrich SA: A molecular signature of radiosensitivity (rsi) is an rt-specific biomarker in prostate cancer. Int J Radiat Oncol Biol Phy 90 (Suppl): S157, 2014.

16. Creelan B, Eschrich SA, Fulp WJ and Torres-Roca JF: A gene expression platform to predict benefit from adjuvant external beam radiation in resected non-small cell lung cancer. Int J Radiat Oncol Biol Phys 90 (Suppl): S76-S77, 2014.

17. Torres-Roca JF, Fulp WJ, Caudell JJ, Servant N, Bollet MA, van de Vijver M, Naghavi AO, Harris EE and Eschrich SA: Integration of a radiosensitivity molecular signature into the assessment of local recurrence risk in breast cancer. Int $\mathrm{J}$ Radiat Oncol Biol Phys 93: 631-638, 2015.

18. Strom T, Hoffe SE, Fulp W, Frakes J, Coppola D, Springett GM, Malafa MP, Harris CL, Eschrich SA, Torres-Roca JF and Shridhar R: Radiosensitivity index predicts for survival with adjuvant radiation in resectable pancreatic cancer. Radiother Oncol 117: 159-164, 2015

19. Ahmed KA, Fulp WJ, Berglund AE, Hoffe SE, Dilling TJ, Eschrich SA, Shridhar R and Torres-Roca JF: Differences between colon cancer primaries and metastases using a molecular assay for tumor radiation sensitivity suggest implications for potential oligometastatic SBRT patient selection. Int J Radiat Oncol Biol Phys 92: 837-842, 2015.

20. Ahmed KA, Chinnaiyan P, Fulp WJ, Eschrich S, Torresroca JF and Caudell JJ: The radiosensitivity index predicts for overall survival in glioblastoma. Oncotarget 6: 34414-34422, 2015.

21. Eschrich SA, Pramana J, Zhang H, Zhao H, Boulware D, Lee JH, Bloom G, Rocha-Lima C, Kelley S, Calvin DP, et al: A gene expression model of intrinsic tumor radiosensitivity: Prediction of response and prognosis after chemoradiation. Int J Radiat Oncol Biol Phys 75: 489-496, 2009.
22. Corneil TA, Kuyper LM, Shoveller J, Hogg RS, Li K, Spittal PM, Schechter MT and Wood E: Unstable housing, associated risk behaviour, and increased risk for HIV infection among injection drug users. Health Place 12: 79-85, 2006.

23. Kempe P, Van Oppen P, De Haan E, Twisk JW, Sluis A, Smit JH, van Dyck R and van Balkom AJ: Predictors of course in obsessive-compulsive disorder: Logistic regression versus Cox regression for recurrent events. Acta Psychiatr Scand 116: 201-210, 2007.

24. Huang DW, Sherman BT and Lempicki RA: Systematic and integrative analysis of large gene lists using DAVID bioinformatics resources. Nat Protoc 4: 44-57, 2009.

25. Huang DW, Sherman BT and Lempicki RA: Bioinformatics enrichment tools: Paths toward the comprehensive functional analysis of large gene lists. Nucleic Acids Res 37: 1-13, 2009.

26. Subramanian A, Tamayo P, Mootha VK, Mukherjee S, Ebert BL, Gillette MA, Paulovich A, Pomeroy SL, Golub TR, Lander ES and Mesirov JP: Gene set enrichment analysis: A knowledge-based approach for interpreting genome-wide expression profiles. Proc Natl Acad Sci USA 102: 15545-15550, 2005.

27. Schena M, Battaglia AF and Munoz F: Esophageal cancer developed in a radiated field: Can we reduce the risk of a poor prognosis cancer? J Thorac Dis 9: 1767-1771, 2017.

28. Guo Y, Zhu XD, Qu S, Li L, Su F, Li Y, Huang ST and Li DR: Identification of genes involved in radioresistance of nasopharyngeal carcinoma by integrating gene ontology and protein-protein interaction networks. Int J Oncol 40: 85-92, 2012.

29. Looby E, Abdel-Latif MMM, Morales VA and Kelleher D: Bile acid exposure induces activation of the extracellular signal-regulated kinase and the transcription factor AP-1 in esophageal cancer cells. Gastroenterology 124: A276, 2003.

30. Liu F, Rehmani I, Esaki S, Fu R, Chen L, de Serrano V and Liu A: Pirin is an iron-dependent redox regulator of $\mathrm{NF}-\kappa \mathrm{B}$. Proc Nati Acad Sci USA 110: 9722-9727, 2013.

31. Maher S, Lynamlennon N and Reynolds J: Differential gene expression profiles as markers of radioresistance in esophageal cancer. Cancer Res 68, 2008.

32. Ogawa R, Ishiguro H, Kuwabara Y, Kimura M, Mitsui A, Mori Y, Mori R, Tomoda K, Katada T, Harada K and Fujii Y: Identification of candidate genes involved in the radiosensitivity of esophageal cancer cells by microarray analysis. Dis Esophagus 21: 288-297, 2008

33. Allalunis-Turner MJ, Zia PK, Barron GM, Mirzayans R and Day RS III: Radiation-induced DNA damage and repair in cells of a radiosensitive human malignant glioma cell line. Radiat Res 144: 288-293, 1995.

34. Chen Y, Li Z, Dong Z, Beebe J, Yang K, Fu L and Zhang JT: 14-3-3sigma contributes to radioresistance by regulating DNA repair and cell cycle via PARP1 and CHK2. Mol Cancer Res 15: 418-428, 2017.

35. Pugh TJ, Keyes M, Barclay L, Delaney A, Krzywinski M, Thomas D, Novik K, Yang C, Agranovich A, McKenzie M, et al: Sequence variant discovery in DNA repair genes from radiosensitive and radiotolerant prostate brachytherapy patients. Clin Cancer Res 15: 5008-5016, 2009.

36. Yi HM, Yi H, Zhu JF, Xiao T, Lu SS, Guan YJ and Xiao ZQ: A five-variable signature predicts radioresistance and prognosis in nasopharyngeal carcinoma patients receiving radical radiotherapy. Tumor Biol 37: 2941-2949, 2016.

37. Bing Z, Tian J, Zhang J,Li X, Wang X and Yang K: An integrative model of miRNA and mRNA expression signature for patients of breast invasive carcinoma with radiotherapy prognosis. Cancer Biother Radiopharm 31: 253-260, 2016.

38. Zhou J, Wu X, Li G, Gao X, Zhai M, Chen W, Hu H and Tang Z: Prediction of radiosensitive patients with gastric cancer by developing gene signature. Int J Oncol 51: 1067-1076, 2017.

39. Vasireddy RS, Sprung CN, Cempaka NL, Chao M and Mckay MJ: $\mathrm{H} 2 \mathrm{AX}$ phosphorylation screen of cells from radiosensitive cancer patients reveals a novel DNA double-strand break repair cellular phenotype. Br J Cancer 102: 1511-1518, 2010.

40. Jacobs KM, Misri S, Meyer B, Raj S, Zobel CL, Sleckman BP, Hallahan DE and Sharma GG: Unique epigenetic influence of $\mathrm{H} 2 \mathrm{AX}$ phosphorylation and $\mathrm{H} 3 \mathrm{~K} 56$ acetylation on normal stem cell radioresponses. Mol Biol Cell 27: 1332-1345, 2016.

41. Jaiswal R, Raymond Grau GE and Bebawy M: Cellular communication via microparticles: Role in transfer of multidrug resistance in cancer. Future Oncol 10: 655-669, 2014.

This work is licensed under a Creative Commons Attribution-NonCommercial-NoDerivatives 4.0 International (CC BY-NC-ND 4.0) License. 